\title{
A OUTRA FACE DA RESPONSABILIDADE SOCIAL EMPRESARIAL
}

Gisele Dayane Milani

Discente do curso de Serviço Social das Faculdades Integradas “Antônio Eufrásio de Toledo" de Presidente Prudente. E-mail: giselemilani@hotmail.com.

\section{RESUMO}

O presente artigo tem por objetivo explanar reflexões acerca da Responsabilidade Social desenvolvida pelas empresas. O surgimento das práticas socialmente responsáveis está ligado à questão do marketing social e imbricado às vantagens competitivas que a empresa pode alcançar em relação à sua imagem. Foi discutida ainda, a outra face da Responsabilidade Social onde foi realizada uma análise crítica em torno do tema. Para tanto, a metodologia utilizada contemplou pesquisas bibliográfica e eletrônica.

Palavras-chave: Marketing Social. Responsabilidade Social. Vantagens Competitivas.

\section{INTRODUÇÃO}

Este artigo é resultado de pesquisas realizadas para o trabalho de conclusão de curso sobre a Responsabilidade Social Empresarial. Este tema tem relevância social e acadêmica por ser um tema atual e com pouco referencial teórico no que diz respeito a outra face Responsabilidade Social Empresarial, ou seja, a crítica em relação a temática.

Esta é uma pesquisa bibliográfica que abrangeu o estudo e análise de referenciais teóricos acerca da Responsabilidade Social, universo do trabalho. A pesquisa bibliográfica foi importante para se conhecer e analisar as principais contribuições existentes em torno do tema da pesquisa. A investigação nesse tipo de pesquisa possibilita o levantamento das teorias produzidas e do conhecimento disponível no assunto, a fim de analisá-las e criar reflexões sobre o objeto da investigação.

Dessa forma, para atingir o objetivo da pesquisa, a metodologia utilizada contemplou as pesquisas bibliográfica e eletrônica. Foi utilizado o método Dialético, pois se sustenta em um processo contínuo de mudanças e tudo é considerado como um complexo de processos que estão sempre em constante transformação.

A partir de uma análise histórica, foi possível notar que a responsabilidade social empresarial emergiu quando o próprio capitalismo estava em fase de desenvolvimento, momento em que as empresas observaram que para garantir a competitividade e seu objetivo final, ou seja, o lucro, apenas a qualidade dos produtos não seria mais suficiente. 
Apresentou-se ainda uma discussão sobre a outra face da Responsabilidade Social Empresarial, destacando-se que as organizações notaram que importar-se com o meio social onde reside seu consumidor é uma boa estratégia para os negócios e agrega valor ao seu produto sempre visando a obtenção e ampliação do lucro. Sendo assim, como todo o discurso do empresariado sobre as ações socialmente responsáveis tem um interesse econômico, nessa oportunidade foi realizada uma análise crítica dessa nova estratégia.

\section{RESPONSABILIDADE SOCIAL DAS EMPRESAS: DIMENSÕES HISTÓRICAS E CONCEITUAIS}

Cabe apontar, que o esforço dessa construção teórica demarca apenas alguns eventos e períodos de destaque da trajetória histórica da Responsabilidade Social, a fim de conduzir a compreensão acerca da temática e no tocante à área social, o que justifica alguns saltos em determinados períodos.

A Responsabilidade Social Empresarial emerge em um contexto de reestruturação do setor produtivo, problemas de ordem social, fragmentação da máquina estatal juntamente com a impossibilidade do mercado em dar respostas aos problemas sociais.

Esse cenário trouxe a emergência de medidas de enfrentamento para as questões e problemas sociais que se colocavam e dos novos desafios gerenciais dos negócios. Dessa forma, os investimentos na área social foram se consolidando e a iniciativa do setor privado passou a ganhar maior visibilidade.

No que se refere ao significado de Responsabilidade Social Empresarial, a conceituação mais difundida é de autoria do Instituto $\operatorname{Ethos}^{1}$ (s.d.; s.p.):

Responsabilidade social empresarial é a forma de gestão que se define pela relação ética e transparente da empresa com todos os públicos com os quais ela se relaciona e pelo estabelecimento de metas empresariais que impulsionem o desenvolvimento sustentável da sociedade, preservando recursos ambientais e culturais para as gerações futuras, respeitando a diversidade e promovendo a redução das desigualdades sociais.

A citação supramencionada é difundida no meio empresarial e propagada como uma relação ética e transparente entre os denominados stakeholders ${ }^{2}$. Demonstra ainda um olhar

\footnotetext{
${ }^{1} \mathrm{O}$ Instituto Ethos de Empresa e Responsabilidade Social (s.p.;s.d.) é caracterizado como uma Organização da Sociedade Civil de Interesse Público Oscip - sem fins lucrativos que possui como missão a mobilização e sensibilização para ajudar empresas a conduzir seus negócios de maneira socialmente responsável e como parceiras visando a construção de uma sociedade mais justa e sustentável. O Instituto Ethos foi criado em 1998 por empresários da iniciativa privada e atualmente é um polo de troca de experiências, de conhecimento, de desenvolvimento de ferramentas que auxiliam as empresas nas suas práticas de gestão, de compromisso com a responsabilidade social, bem como com o desenvolvimento sustentável. $\mathrm{E}$ ainda, o instituto Ethos é referência internacional no que tange os assuntos mencionados e possui destaque em segmentos do empresariado, da sociedade civil e de instituições acadêmicas.
} 
para a natureza a partir de metas visando o desenvolvimento sustentável, denota preocupação com as gerações futuras e se compromete a promover a redução das desigualdades sociais.

No entanto, a dúvida que persiste é sobre as reais intenções de diferentes empresas em torno dessa nova forma de gestão as quais, por vezes, denotam maior interesse pelo marketing e pela imagem da empresa do que pela intenção de poupar recursos ambientais, etc. Compreende-se que essa conceituação representa uma estratégia de convencimento das classes mais abastadas que estariam supostamente preocupadas com as desigualdades sociais, sendo que, contraditoriamente, a atuação da empresa proporciona a exploração da força de trabalho e dependendo do ramo de atividade também degradação do meio ambiente revelando assim um discurso e uma prática contraditórios.

O escopo de discussões sobre o tema em tela abrange uma gama de problemas de ordem social, decorrentes de demandas e temas emergentes vivenciados na contemporaneidade. No entanto, o que realmente motiva a adoção de um comportamento socialmente responsável no trato com a gestão dos negócios vai além da contribuição para uma sociedade mais justa ou da busca da sustentabilidade. Entende-se que a outra face da responsabilidade social está permeada por interesses privados, comerciais e de âmbito econômico, que trazem como principais vantagens a melhora da imagem institucional e a valorização da marca.

\subsection{A Outra Face da Responsabilidade Social Empresarial}

Diante da discussão apresentada acima, é possível notar que as empresas buscam na área ambiental e social estratégias com o intuito de construir sua imagem de forma diferenciada. As organizações notaram que importar-se com o meio social onde reside seu consumidor é uma boa estratégia para agregar valor ao seu produto visando a obtenção e ampliação do lucro.

Para Cesar (2008, p. 250), a responsabilidade social é uma estratégia fundamental voltada à sustentabilidade nos negócios e:

[...] implica investimentos da empresa em programas sociais que, em tese, se voltam para 'o exercício da cidadania e para a construção de uma sociedade democrática, equânime e solidária'. As intervenções das empresas na área social são consideradas fundamentais, portanto, para a redução das desigualdades no país e para alavancagem do 'desenvolvimento sustentável' em nível local, regional e nacional.

\footnotetext{
${ }^{2}$ De acordo com Rico (2010, s.p.) os stakeholders são os diversos públicos com os quais a empresa se relaciona composto por: funcionários, consumidores, acionistas, prestadores de serviços, fornecedores, governo, comunidade e meio ambiente. 
Assumir investimentos em programas sociais, ou em projetos sociais passa a ser imprescindível para as empresas que desejam se manter no mercado e ganhar ainda mais espaço. A prática de gestão dos negócios com vistas à intervenção das empresas na área social torna a empresa respeitada socialmente, mesmo que ela esteja apenas cumprindo as obrigações legais e esteja utilizando isso como discurso de responsabilidade social. Ou ainda, que disponha de ações, porém sem continuidade e estejam mais caracterizadas como jogada de marketing - todas vão repercutir na imagem institucional.

No entanto, cabe ressaltar que essas práticas também devem propiciar contribuições para a área social, não podendo apenas permanecer no campo dos interesses empresarias. É uma via de mão dupla, ao passo que no desenvolvimento das ações com o intuito de melhorar a imagem institucional, contribuir para o marketing da empresa e de seus produtos, o viés social deve estar presente para além do cumprimento de normas legais, deve proporcionar impacto social e transformar práticas isoladas em políticas continuadas.

Notam-se no cenário empresarial, novas e velhas formas de controle da força de trabalho, que potencializam a produtividade, conforme citação a seguir:

É o desenvolvimento de projetos pautados em seres humanos, de acordo com seus princípios básicos e focados em temas que tragam ganhos para todos: sociedade, governos, trabalhador e para a empresa [...]. É um dos mais importantes modos de identificação. Ela tem como prioridade, investir na área social, nas condições de seus empregados, motivando seus colaboradores para um comprometimento pessoal e profissional, no sentido da melhoria contínua da qualidade e produtividade [...]. É estabelecer uma verdadeira parceria entre capital-trabalho, empresafuncionários, desenvolver uma politica empresarial-industrial com sistemas e métodos inovadores. É a implantação das atividades em pequenos grupos; é o trabalho humanizado, uns com os outros, cooperação, consenso e união. (CESAR, 2008, p. 251)

Convém ressaltar, mais uma vez, que a longa tradição das empresas denota seu envolvimento com estratégias em investimentos que the tragam retorno financeiro, o que continua se evidenciando no trato com a responsabilidade social. Entretanto, projetos e ações sociais devem ser implementados e desenvolvidos visando à melhoria das condições de vida e o desenvolvimento social e econômico. A execução de projetos sociais que propiciem efetivo impacto naquilo a que se propõem vão repercutir de forma positiva na imagem da empresa junto à sociedade e ao mercado consumidor. 
Em termos de gestão dos negócios, a preocupação empresarial está dirigida aos efeitos imediatos que a prática de responsabilidade social trará junto ao público, na divulgação da marca e na almejada lucratividade. Nesse sentido, existe uma sintonia entre os investimentos sociais propostos pelas organizações privadas e a perspectiva de alcançarem os resultados almejados em lucratividade com estes.

Nesse sentido, Rico (2004, p. 74) afirma que "As organizações empresarias têm como tendência financiar atividades, dando preferência àquelas relacionadas com os bens e serviços que produzem ou comercializam". Fica evidente, portanto, o uso estratégico do investimento no social como um diferencial de competitividade ligado ao interesse econômico dos empresários e ao reconhecimento das ações por parte da sociedade. Mas, o fato das organizações terem como tendência financiar atividades de acordo com seu negócio também está voltado à sua própria sobrevivência sendo assim uma demonstração de visão estratégica.

No entanto, persiste a dúvida: serão essas práticas apenas instrumentos de marketing ou realmente podem produzir e produzem mudanças no cenário social onde estão atuando? Este questionamento vem de encontro à afirmação de Costa Filho (2004, p. 76) "Afinal, se por um lado a sociedade cobra uma postura social e ambientalmente responsável, por outro, recompensa as empresas que trabalham em prol desses ideais".

A questão da responsabilidade social empresarial ainda é considerada um tema recente, dinâmico e polêmico, pois historicamente, as empresas atuavam somente com responsabilidades atreladas à função econômica de acumulação e reprodução do capital.

O setor empresarial passa a atender às necessidades da comunidade, sob o discurso da responsabilidade social, desenvolvendo projetos aliados a prática voluntária e constituindo parcerias com o poder público e com diversas organizações, encontrando apoio gerado pela Reforma do Estado que, ao instituir um "espaço público não estatal" permite às diversas organizações ganharem espaços na área social. Tal fato possibilitou às organizações privadas a prestação de serviços sociais com base na gestão da solidariedade, filantropia e espírito comunitário.

O reconhecimento público das ações de responsabilidade social também se expressa por meio de premiações, selos, menções e certificações. Dessa forma, o reconhecimento articula-se com a divulgação da empresa para o mercado e a sociedade, como forma estratégica de reorganização das práticas empresariais que passam a ser vistas não mais como aquela que explora o trabalho ou que depreda os recursos ambientais. 
Em relação às parcerias do Estado com as organizações da sociedade civil e do mercado no que tange a área social, é interessante destacar que mais que a retirada estratégia de cena estatal, tal fato encobre o processo de vulnerabilização de um legado de direitos sociais.

Ao analisar-se o discurso de comportamento ético e responsável das empresas, observou-se que estas vão delineando uma nova estratégia ao conciliar lucro e ética, pois obtém grandes ganhos, o que torna essa postura ética presente no discurso da responsabilidade social apenas um instrumento com propósitos meramente calculistas. E ainda, a responsabilidade social empresarial passou a divulgar amplamente palavras em defesa da cidadania, da participação social, da solidariedade e da parceria para o enfrentamento dos problemas sociais, com o intuito real de facilitar o alcance de grandes níveis de acumulação.

A responsabilidade social acaba por colaborar no ocultamento das causas desses problemas sociais que diz combater. Reforça, ainda que nem sempre intencionalmente, a visão de que os problemas são causados pela própria incapacidade dos indivíduos e grupos empobrecidos, em decorrência de sua falta de vontade, falta de educação/ orientação, etc.

Um dos desafios nas ações empreendidas pelas organizações refere-se ao "Como empreender ações eficientes do ponto de vista da estratégia empresarial e que, ao mesmo tempo, não quebrem a harmonia entre a empresa e aqueles dos quais ela depende e os que dependem dela [...]" (COSTA FILHO, 2004, p. 19). Assim, é possível notar a contradição entre ser uma empresa socialmente responsável ao mesmo tempo em que se visa garantir lucro nos negócios. É desafiante garantir a harmonia para ambas as partes interessadas nesse meio, ou seja, a instituição privada e a área social.

O que não deve ser descartado, no entanto, é a força potencializadora que as empresas possuem para desenvolver as ações sociais, pois já estão postas e não podem ser negadas. O contrário de negá-las, é afirmar que elas precisam ser politizadas, incrementadas e potencializadas para que tragam os resultados que se propõem ao meio social e, consequentemente, o retorno esperado.

Por projeto de responsabilidade social entende-se uma articulação entre a missão da empresa, em consonância com seus pressupostos éticos-políticos com a maneira como a mesma se relaciona com os empregados, entre outros. Dessa forma, entende-se que o real engajamento das práticas socialmente responsáveis aduz que um projeto social bem sucedido tem como consequência o reconhecimento institucional, do público que atinge e da comunidade em torno. 
Enfim, por meio do investimento no social a empresa constrói uma imagem positiva e pode ainda contribuir diretamente no âmbito comunitário provocando impactos positivos.

\section{CONSIDERAÇÕES FINAIS}

A Responsabilidade Social emergiu no contexto de reestruturação produtiva, fragmentação da máquina estatal e expansão do terceiro setor. Verificou-se que o que impulsionou o empresariado a adotar um comportamento socialmente responsável no trato com a gestão dos negócios está mais além da contribuição para uma sociedade mais justa ou da busca da sustentabilidade. O que remete ao entendimento de que a outra face da Responsabilidade Social está permeada de interesses privados, comerciais e de âmbito econômico, que trazem como principais vantagens a melhora da imagem institucional e a valorização da marca.

Dessa forma, a partir de uma análise teórica foi possível perceber que, no discurso as empresas dizem combater a desigualdade, mas são as maiores produtoras e reprodutoras desta. Sendo assim, fala-se em desigualdade social e em pobreza, mas nunca em redistribuição da renda e da riqueza socialmente produzida.

E ainda, que os efeitos globais desse novo padrão de intervenção social se expressem na despolitização da sociedade, o contentamento com a ajuda ofertada favorece a estabilidade do sistema social. Como resultado, temos ações fragmentadas, localizadas e sujeitos escolhidos e favorecidos aleatoriamente.

\section{REFERÊNCIAS}

ALESSIO, Rosemeri. Responsabilidade social das empresas no Brasil: reprodução de postura ou novos rumos? Porto Alegre: EDIPUCRS, 2008.

BEGHIN, Nathalie. A filantropia empresarial: nem caridade, nem direito. São Paulo: Cortez, 2005.

BRASIL. Organizações da Sociedade Civil. Lei n 9.790, de 23 de Março de 1999. Brasília, DF, Senado, 1999.

CESAR, Monica de Jesus. Empresa Cidadã: uma estratégia de hegemonia. São Paulo: Cortez, 2008.

COSTA FILHO, Adalberto Vieira. Responsabilidade social das empresas: a contribuição das universidades. São Paulo: Peirópolis, 2004.

ETHOS, Instituto. O que é RSE. Disponível em: <http://www1.ethos.org.br/EthosWeb/pt/29/o_que_e_rse/o_que_e_rse.aspx>. Acesso: 12 mar. 2012. 
RICO, Elizabeth de Melo. A responsabilidade social empresarial e o Estado: uma aliança para o desenvolvimento sustentável. São Paulo Perspec. vol.18 no.4 São Paulo Oct./Dec. 2004.

Disponível em: <http://www.scielo.br/scielo.php?script=sci_arttext\&pid=S010288392004000400009>. Acesso 13 ago. 2012.

RICO, Elizabeth de Melo. RESPONSABILIDADE SOCIAL EMPRESARIAL E SUSTENTABILIDADE (percursos em Portugal). Revista Administração em Diálogo Programa de Estudos Pós-Graduados em Administração Pontifícia Universidade Católica de São Paulo. Publicado em Maio de 2010. Disponível em: <revistas.pucsp.br/index.php/rad/article/download/2936/1894>. Acesso 27 jul. 2010.

TENÓRIO, Fernando Guilherme (Org.). Responsabilidade social empresarial: teoria e prática. 2. ed. rev. e ampl. Rio de Janeiro: FGV, 2006. 